\title{
Recursos minerais do município de Santa Maria
}

\author{
Carlos Alberto da Fonseca Pires \\ Luis Eduardo Robaina \\ LAURINDO BERTOLdo
}

\begin{abstract}
Brazil has its wide diversification of natural resources, due to geology of each area. It includes the mining as a process that gathers an economic progress and at the same time, it cannot, to cause unbalances and aggressions to the environment. The municipal district of Santa Maria in its mineral potential, seeking to the creation of immediate employment, linked mainly to the civil construction, developed essentially in extraction of clay, sands and the mineral water. The visual impact caused by the activity of mineral extraction change the municipal image, mainly due the ciliate forest extraction and the erosion. Than, the recovery of these areas becomes slower and complex. The mineral extraction in this district quest the economic and social development and supportability of resources in a pragmatic way relate with the industry of civil construction.
\end{abstract}




\section{RESUMO}

O Brasil tem ampla diversificação de recursos naturais, devido a geologia de cada região, engloba a mineração como um processo que reúne um avanço econômico e ao mesmo tempo pode causar desequilíbrios e agressões ao meio ambiente. O município de Santa Maria, no seu potencial mineral e visando à criação de empregos imediatos ligados principalmente àqueles relacionados com a construção civil, que desenvolvem prioritariamente as lavras de argilas, areias e de água mineral. $\mathrm{O}$ impacto visual causado pela atividade de extração mineral muda a imagem do município, principalmente, devido a extração da mata ciliar e devido a erosão decorrente, tornando a recuperação destas áreas lentas e complexas.

A extração mineral, nesse município, busca o desenvolvimento econômico e social, na sustentabilidade dos recursos relacionada com a indústria da construção civil.

\section{INTRODUÇÃO}

O Brasil possui um grande potencial mineral devido à diversidade de recursos, que se encontram distribuídos pelo território, conforme a geologia de cada região. Esses recursos, a partir da exploração, se tornam riquezas para a União ou para a iniciativa privada, mas muitas vezes as extrações não seguem as técnicas e leis ambientais e causam impacto para o meio ambiente e graves problemas a uma determinada população, quer seja pela devastação ou pelo uso exploratório indevido. A mineração, como processo econômico produtivo, gera, sem dúvida, desequilíbrios e agressões intrínsecas ao meio natural; no entanto, constitui uma atividade de produção primária que atende a mais de $90 \%$ das exigências da vida moderna.

Dentro das normas atuais, os municípios passam a ter maiores responsabilidades e devem assumir sistemático planejamento de seu espaço territorial e de seu próprio desenvolvimento. Neste sentido, é fundamental o trabalho de levantamento e de organização de dados, permitindo otimizar os projetos de ocupação do solo que auxiliem na avaliação da real afinidade econômica das regiões e dos municípios.

A dinâmica do atual trabalho é mostrar a influência que a produção dos recursos minerais ocupam no espaço geográfico do município de Santa Maria, caracterizando, determinando e mapeando 
os bens minerais, que estão licenciados para serem extraídos pelas empresas cadastradas no DNPM.

Os recursos minerais com ocorrência na área em estudo têm uso diverso, desde insumos para indústria na construção civil até minerais estratégicos de grande valor econômico (argilas nobres para fabricação de material cerâmico ou areia para fabricação de vidro, etc.).

\section{CARACTERIZAÇÃO DA ÁREA}

A área de estudo está localizada entre as coordenadas de $29^{\circ} 32^{\prime}$ e $30^{\circ} 02^{\prime}$ de latitude sul e $54^{\circ} 08^{\prime}$ e $53^{\circ} 30^{\prime}$ de longitude oeste, (figura 1), na parte central do Estado do Rio Grande do Sul, e está inserida no compartimento geológico-geomorfológico da Depressão Periférica, sendo que o limite norte da área estende-se sobre o rebordo do Planalto Meridional e o limite sul estende-se sobre Escudo Sul-rio-grandense.

O município de Santa Maria situa-se sobre os sedimentos continentais derrames vulcânicos, de idade triássica-jurássica. Os sedimentos fazem parte do Grupo Rosário do Sul, Formação Santa Maria e Formação Botucatu, enquanto as vulcânicas são pertencentes à Formação Serra Geral. Os primeiros são constituídos por sedimentos arenosos (Grupo Rosário do Sul, parte basal da Formação Santa Maria e Formação Botucatu) e por sedimentos finos, representados por lamitos, pertencentes à parte superior da Formação Santa Maria. As rochas vulcânicas são representadas por Derrames básicos (basalto) até ácidos (riodacitos).

Geomorfologicamente, os sedimentos distribuem-se em faixas mais ou menos estreitas (entre 2 e $20 \mathrm{Km}$ ), com orientação aproximadamente leste-oeste. Com exceção da Formação Botucatu, apresentam-se formando colinas suaves, com fracos desniveis entre os interflúvios e os talvegues. Acompanham de um modo geral, os contornos da escarpa da Serra Geral, onde afloram, principalmente, as rochas vulcânicas de mesmo nome e os arenitos eólicos da Formação Botucatu.

Em termos de hidrografia, a região de Santa Maria, comporta-se com o divisor de águas das duas grandes bacias hidrográficas do Estado do Rio Grande do Sul: a do Jacuí e a do Ibicuí.

Dentro do aspecto político, Santa Maria faz fronteira, ao Norte, com os municípios de São Martinho da Serra e Itaára; a Nordeste, com Júlio de Castilhos e Silveira Martins e, a Noroeste com a cidade de São Pedro do Sul. Já, a Leste, o município vizinho 
é Restinga Seca e a Oeste Dilermando de Aguiar. Na parte meridional do município, fazem fronteira, a Sudeste, o município de Formigueiro, ao Sul São Sepé e a Sudoeste São Gabriel. Esses limites têm grande relevância para o trabalho, uma vez que as recentes emancipações dos municípios, modificaram áreas importantes na extração de basalto e gemas (ametista e ágata). Como exemplos, o município de Itaára com a maior parte do território com produção de basalto e o município de Dilermando de Aguiar com a maior parte da área de extração de gemas (ametista e ágata).
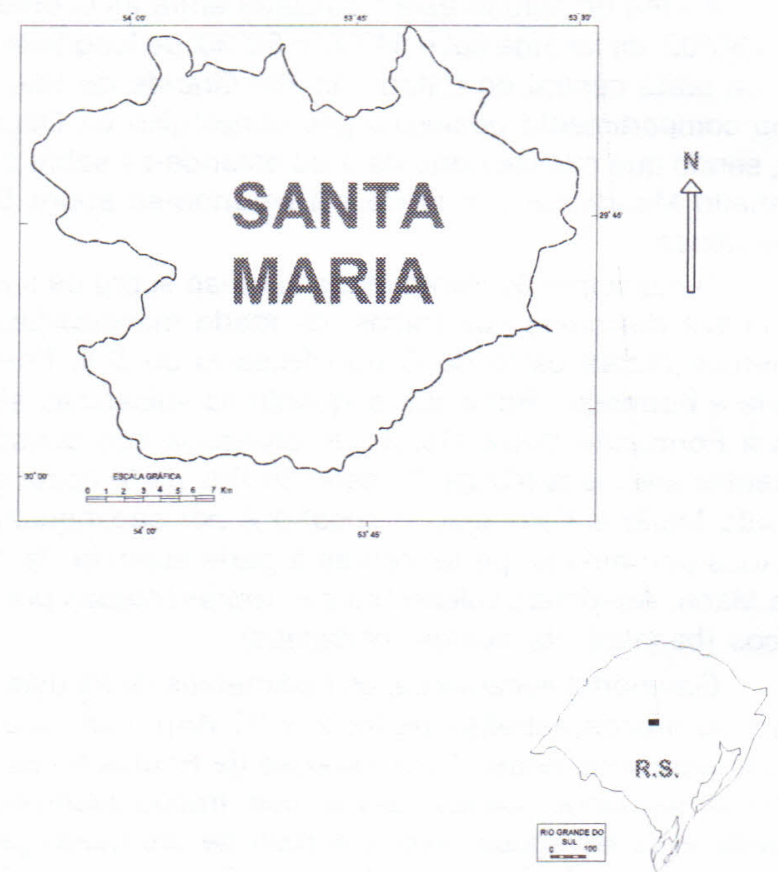

Fig. 1. Localização da área de estudo ( Santa Maria - RS).

\section{METODOLOGIA}

O trabalho constou das seguintes etapas: i) delimitação da área de estudo a partir de cartas topográficas; ii) levantamento de áreas licenciadas com os respectivos bens minerais, junto ao cadastro do Departamento Nacional de Produção Mineral; iii) listagem de empresas licenciadas para atividade de extração mineral no município de Santa Maria; iv) registro fotográfico representativo das áre- 
as de extração de recursos minerais no município; v) comparação entre atividade de extração desses recursos e outras atividade econômicas no município. Esses dados serviram para estabelecer a relação da extração mineral com outras atividades econômicas, como comércio, prestação de serviços, indústria e agropecuária, bem como para verificar a representação e importância da atividade no conjunto do setor produtivo do município.

\section{RESULTADOS E DISCUSSÕES}

O licenciamento, para extração de bens minerais em Santa Maria, segundo levantamento no DNPM, indica sete recursos minerais (tabela 1): água mineral, areia, argila, basalto, gema (ametista e ágata), granito e saibro. Os trabalhos de campo e análise das substâncias licenciadas permitiram as seguintes considerações: 1) Gemas (ametista e ágata) e o saibro: as áreas licenciadas para extração desses bens minerais, não apresentam atividade de extração dos bens minerais licenciados; 2) granito e o ouro: existem cinco licenciamentos, porém a característica geológica da região é incompativel com a ocorrência desses bens minerais; 3) caulim: nas extensas áreas citadas pelo DNPM não há registro da ocorrência desse bem mineral; 4) basalto e diabásio: apenas em parte, encontramse inseridas na área de estudo. Isso ocorre, principalmente, devido à emancipação de Itaára, onde as atividades de extração de basalto eram intensas e ficaram contidas no seu território, certamente devem ter importância econômica relevante para esse novo município.

Assim, restam no município de Santa Maria a areia, a argila e a água mineral. A areia e a argila são os bens minerais com o maior números de áreas licenciadas, e também área com atividade de extração mineral. Para extração de areias estão licenciadas 37 áreas ou $44 \%$ das licenças, enquanto para extração de argila, 22 áreas ou $27 \%$. Assim, a extração de areia e de argila chega a $71 \%$ da produção o que comprova a importância desses dois bens minerais para o município de Santa Maria, conforme mostrado na figura 2.

O potencial mineral de Santa Maria na produção de bens minerais para o emprego imediato na indústria de construção civil, ou para a indústria de cerâmica, enquadrando-se no grupo dos materiais primários de construção e minerais industriais não-metálicos. Os trabalhos de mineração que se desenvolvem no município são principalmente: i) lavras de argilas para a indústria de cerâmica (teIhas, tijolos) e ii) areias. 
Tab. 1. Histórico das Áreas Licenciadas na Extração Mineral em Santa Maria (1981 - 2001)

(Fonte: DNPM - Montagem: Laurindo Bertoldo)

\begin{tabular}{ccc}
\hline Subsância & $\mathbf{n}^{\circ} \mathbf{d e}$ alvarás & Á rea e $\mathbf{~ h a ~}$ \\
\hline Água Mineral & 4 & 197,55 \\
A reia & 42 & 474,85 \\
A rgila & 22 & 287,42 \\
B asalto & 7 & 244,75 \\
Caulim & 2 & 1906,47 \\
Gema (ametista e ágata) & 1 & 1000,00 \\
Granito & 1 & 50 \\
Saibro & 3 & 13,66 \\
Ouro & 4 & $\mathbf{4 3 4 6 , 5 9}$ \\
Total & $\mathbf{8 6}$ &
\end{tabular}

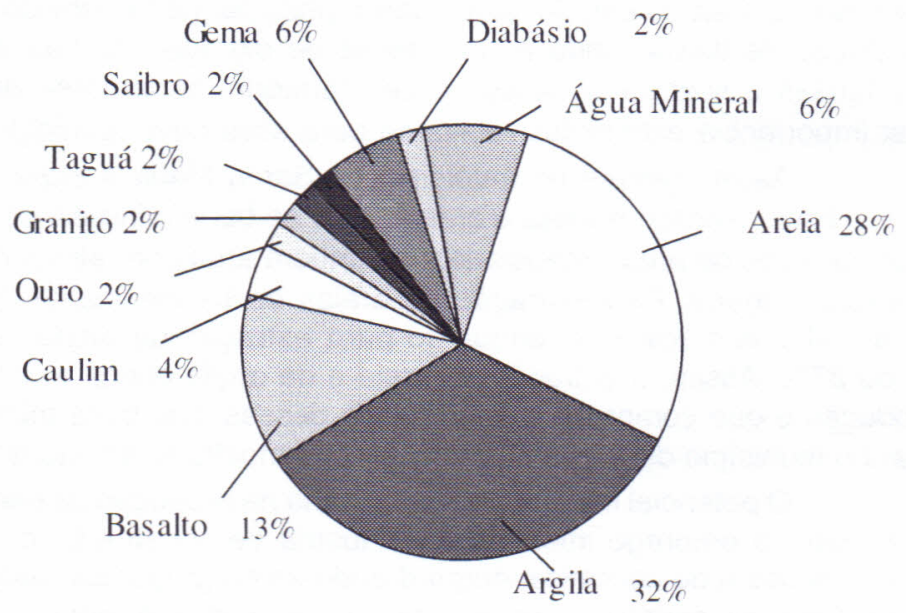

Fig. 2. Número de áreas por atividade de extração mineral (dados referentes ao ano de 2001)

(Fonte: DNPM- Montagem: Laurindo Bertoldo) 
As argilas têm largo uso industrial, quer como matériaprima fundamental ou então como componente acessório na indústria. Santas (1975) lista diversos usos das argilas:

- a indústria cerâmica usa argilas na fabricação de cerâmica vermelha (tijolos, ladrilhos para piso, lajes e material ornamental), de cerâmica branca (material sanitário, louça doméstica, azulejo e pastilhas, porcelana doméstica, de laboratório) e de material refratário (sílico-aluminosos e aluminosos);

- as indústrias de papel e papelão que usam como carga e cobertura;

- as indústrias de borracha e plástico que as utilizam como carga ativa e inerte;

- a indústria metalúrgica que usa argila como aglomerante de areias de moldagem para a fundição de metais e para pelotização de minério de ferro;

- a indústria de tintas que utiliza argilas como diluente primário e secundário (pós-inertes) para inseticidas;

- as indústrias de óleos comestíveis e de derivados de petróleoque utilizam argilas como agentes descorantes de óleos vegetais e minerais;

- argilas especiais são usadas como catalisadores no craqueamento de petróleo para produção de gasolina.

Em Santa Maria o uso industrial da argila se restringe à fabricação de materiais de uso na construção civil: tijolos, telhas, etc.

Assim como argila, a areia é um bem mineral de grande importância no município de Santa Maria. A Figura 3 apresenta as empresas de extração de areia e a área, observa-se que:

A empresa de Gilberto Antolini, como a detentora da maior área e do maior número de áreas licenciadas na atividade de extração de areia, sua área representa $42,25 \%$ do total da área destinada a extração de areia. Informações obtidas junto à direção dessa empresa informam que o recurso mineral extraído é comercializado, quase na sua totalidade, nos municípios da região (Cruz Alta, ljuí entre outros).

Observa-se que algumas áreas licenciadas são arrendadas pelos solicitantes originais, inclusive grandes áreas, que representa, em alguns casos, mais de $20 \%$ das áreas de extração de areia. Conforme a figura 3 , é possivel ver a concentração, também na atividade de extração de areia, onde a área da maior empresa é mui- 
to maior do que a soma das áreas das pequenas empresas.

As empresas extratoras de areia arrecadaram no ano de 1996, segundo declaração de seus proprietários, no um total de Cr\$ 9.930.664,00 enquanto as empresas extratoras de argila arrecadaram $\mathrm{Cr} \$ 5.471 .998,00$. Essa movimentação financeira, se comparada com a arrecadação de impostos da prefeitura de Santa Maria nesse mesmo ano, corresponde a 20,32\% (areia) e 11,19\% (argila), respectivamente (Silva, 1997). Esta comparação levou em conta os valores declarados pelos responsáveis técnicos das empresas extratoras e que constam no cadastro do CREA-RS (Conselho Regional de Engenharia, Arquitetura e Agronomia do Rio Grande do Sul). A maior dificuldade desse setor é a fiscalização.

Na geração de empregos, tanto a atividade de extração de areia como a extração de argila apresentam aspectos positivos uma vez que, na ausência de indústrias, o município de Santa Maria sofre com o desemprego crônico. Esse processo produtivo utiliza tanto a mão-de-obra assalariada, como mão-de-obra familiar. A figura 4 mostra a mão-de-obra assalariada corresponde a 91\% (182 trabalhadores) do total da força de trabalho empregada na atividade.

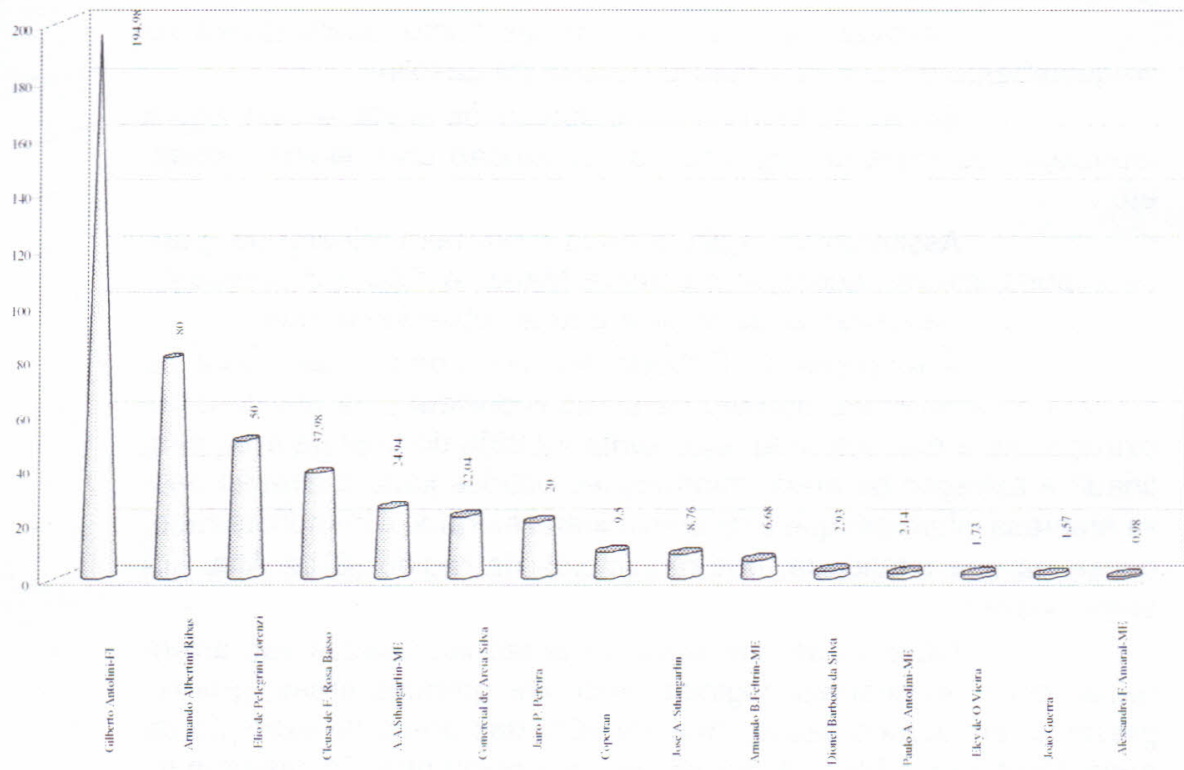

Fig. 3. Empresas licenciadas em Santa Maria para extração de areia (DNPM - 2001 (ha))

Fonte: DNPM - Montagem: Laurindo Bertoldo 


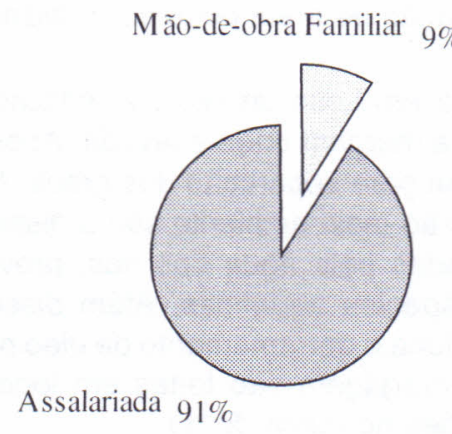

Fig 4. Distribuição da mão-de-obra na atividade de extração de areia e argila - 2001

Fonte: Entrevista as Empresas e (SILVA, 1997)

O uso da draga que é um método que permite a extração permanente é usado por $13 \%$ das empresas É uma tecnologia cara e requer alto investimento. Outro método de extração é através de pá carregadeira, é amplamente usado atingindo $87 \%$.das frentes de lavra (Figura 5).

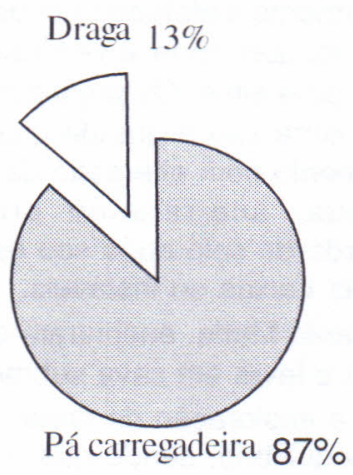

Fig 5: Método de extração por empresa de extração de areia - 2002 Fonte: Entrevista as Empresas Montagem: Laurindo Bertoldo 
A extração de areia pode ser realizada através de quatro tipos de lavras:

- Lavra em Leito de Rios: é realizada por sucção, trazendo a areia para a margem onde é lavada. Após, é feita uma nova dragagem e lavagem para separação dos grãos. Neste tipo de lavra, os danos causados ao meio ambiente são a dispersão de partículas finas, que são levadas pela água dos rios, provocando turbidez e prejudicando as espécies aquáticas. Além disso, o mau uso dos equipamentos ocasiona o derramamento de óleo nos cursos de água. As operações por dragagem são feitas em locais alternados sem provocar modificações no curso do rio.

- Lavra em Cava Seca: é desenvolvida nos bancos de areia, que são derrubados pela água. A areia é lavada por canaletas para a bacia de concentração. Durante esse processo, a areia grossa é separada da fina. Na bacia, a areia é separada por gravidade e dragada por sucção, indo parar em outra bacia, onde é realizada uma segunda lavagem. Os danos nesse tipo de lavra são o desmatamento, a erosão, o escorregamento de talude e o conseqüente assoreamento dos rios.

- Lavra em Cava Submersa: são utilizados equipamentos que desmontam as margens e nos fundos dos rios ou lagos. Em seguida, é realizado um processo semelhante a lavra em leito de rio. Este tipo de extração provoca erosão e assoreamento dos cursos de água e lagos, alterando seus cursos, regimes hídricos e turbidez.

- Lavra em Solo de Alteração: é realizada em rocha alterada do embasamento e efetuada por desmonte hidráulico. A areia é levada para um tanque onde é bombeada para outro tanque e, após, transportada para silos. Os prejuízos causados ao meio ambiente neste tipo de lavra são a grande quantidade de rejeitos da rocha-mãe, assoreamento com alteração da drenagem natural, desvio do curso de água, acarretando problemas de enchente, desmatamento, perda de solo após seu esgotamento e o abandono das cavas em áreas baixas ou instáveis.

Em Santa Maria, encontram-se lavras de leitos de rios, lavra em cava seca e lavra em cava submersa.

Após a exploração da areia, a área alterada passa por um estágio de desequilíbrio, sendo que o ecossistema pode ser recuperado se for estabelecida uma nova condição de equilíbrio. As maiores alterações no meio físico provocadas por lavras de areia são desmatamentos, remoção do solo, cavas abandonadas, alterações 
dos cursos d'água, poluição das águas (material fino em suspensão), e assoreamentos.

\subsection{Minimização dos Impactos Ambientais gerados}

A lavra é uma atividade agressiva ao meio ambiente. No entanto, é possível usar o recurso mineral, minimizando os danos ambientais, isso exige cuidados especiais que são obtidos a partir de orientação técnica adequada. Essa orientação contempla procedimentos que minimizem o impacto visual, que recomponha a cobertura vegetal, que preserve a vegetação ciliar e que as condições ambientais sejam próximas das condições originais. É desejável que topografia do terreno possa ser recomposta, inclusive com a recolocação da camada de solo fértil, rica em matéria orgânica. Algumas vezes isso não é possivel. É indispensável que, em tais situações, alguma atividade econômica ou de lazer seja pensada para destinação dessa área. Isso pode envolver a construção de praça, quadra de esporte, jardim, pomar, atividade de piscicultura, mato nativo para refúgio do gado, etc..

\section{CONCLUSÕES E RECOMENDAÇÕES}

As características geológicas da região de Santa Maria apresentam as atividades de extração de areia e argila, como atividades produtivas de interesse econômico. São atividade geradoras de emprego e estão diretamente relacionadas com a indústrias da construção civil

A extração mineral, em Santa Maria, pode ser um fator de desenvolvimento, desde que executada com uso da técnica adequada e com recuperação ambiental. Essa atividade pode ter significativa relação com a indústria da construção civil. Com geração de empregos diretos e fomento de programas de habitação popular com baixo custo.

A carência de um levantamento detalhado das ocorrências dos diferentes tipos de recursos minerais do município de Santa Maria, além de inviabilizarem o processo de fiscalização dessa atividade produtiva, não permite que o potencial mineral do município seja considerado no projeto de desenvolvimento para o município.

As empresas extratoras de recursos minerais de Santa Maria necessitam de adequado e contínuo acompanhamento técni- 
co para que possam desenvolver suas atividades com o mínimo dano ambiental. Nesse sentido, recomenda-se a criação de associações de pequenos produtores de bens minerais que possa dividir os custos de contratação de profissionais habilitados para prestação de assistência técnica e de aquisição de equipamento para otimização do processo de lavra.

\section{BIBLIOGRAFIA}

AKINAGA, R.M. Palestra de Abertura. In: Seminário Internacional sobre Mineração. Anais, São Paulo, 1989.p.14

BRASIL, Departamento Nacional de Produção Mineral. Código de Mineração e Legislação Correlativa. Ed. ver. Por Humberto de Carvalho Matos Brasília, Divisão de Fomento de Produção Mineral, 1982.

BRASIL, Departamento Nacional de Produção Mineral. Curso de controle da Poluição na Mineração: alguns aspectos. 1986.

CMMAD - Comissão Mundial sobre Meio Ambiente e Desenvolvimento. "Nosso Futuro Comum". $2^{\text {a }}$ ed., Rio de Janeiro, FGV, 1991. P. 49.

CHRISTOFOLETTI, A. Geomorfologia. São Paulo: Edgar Bucher, 1980. FORNASARI $F^{\circ}$,N.; LEITE, C.A.G.; PRANDINI, F.L. \& AZEVEDO, R.M.B. Avaliação Preliminar dos Problemas Causados pela Mineração no Meio Ambiente no Estado de São Paulo. S.n.t.

INSTITUTO BRASILEIRO DO MEIO AMBIENTE E DOS RECURSOS

NATURAIS RENOVÁVEIS - IBAMA. Manual de recuperação de áreas degradadas pela mineração. Técnicas de revegetação. Brasília, 1990.

INSTITUTO BRASILEIRO DE MINERAÇÃO - IBRAM. Mineração e meio ambiente. www.org.ibram.br/com Brasília, 2001.

RECUPERAÇÃO E MANEJO DE ÁREAS DEGRADADAS, 1997.

Campinas. Memória do Workshop. Jaguariúna: EMBRAPA-CNPMA, 1998. 70. (EMBRAPA-CNPMA. Documentos 13).

SILVA, Gustavo Siqueira da Determinação e Mapeamento da Atividade Mineira em Santa Maria, sua Participação na Economia do Município, sua Relação com outras Atividades Econômicas e o Impacto Ambiental. Trabalho de Graduação. UFSM - Santa Maria SCLIAR, C. Minerar é preciso?, Porto Alegre: PUCRS. Anais da $51^{a}$ Reunião Anual da SBPC, 1999. 
Tab. 2. Determinação das empresas de Extração Mineral Licenciadas junto ao Departamento Nacional de Produção Mineral (DNPM) Fonte DNPM Montagem: Laurindo Bertoldo

\begin{tabular}{|c|c|c|}
\hline EMPRESA & $\begin{array}{l}\text { SUBSTANCIA } \\
\text { MINERAL }\end{array}$ & ÁREA (ha) \\
\hline SANTAMATE IND COM IMP E EXP LTDA & Água Mineral/Caulim & 990 \\
\hline EMPRESA MINERADORA IJUI S/A & Água Mineral & 50 \\
\hline LEANDRO SCHWERTNER CHARÃO & Água Mineral & 49 \\
\hline NEIF NOUER JÚNIOR & Água Mineral & 49 \\
\hline DIONEL BARBOSA DA SILVA & Areia & 2,93 \\
\hline GILBERTO ANTOLINI-FI & Areia & 194,98 \\
\hline CLEUSA DE FATIMA ROSA BASSO & Areia & 37,98 \\
\hline JOÃO GUERRA & Areia & 1,57 \\
\hline COMERCIAL DE AREIA SILVA LTDA & Areia & 22,04 \\
\hline ARMANDO BORDIN FELTRIN JUNIOR-ME & Areia & 6,68 \\
\hline COPETRAN-COMERCIO DE PEDRAS E TR & Areia & 9,5 \\
\hline ALESSANDRO FERNANDES AMARAL-ME & Areia & 0,98 \\
\hline ELCY DE OLIVEIRA VIEIRA & Areia & 1,73 \\
\hline ARMANDO ALBERTINI RIBAS-FI & Areia & 80 \\
\hline PAULO AILTON ANTOLINI-ME & Areia & 2,14 \\
\hline A.A STHANGARLIN-ME & Areia & 24,98 \\
\hline JAIRO PIRES PEREIRA & Areia & 20 \\
\hline JOSÉ ALBERTO STHANGARLIN & Areia & 8,76 \\
\hline ELIO DE PELLEGRINI LORENSI-FIRMA & Areia & 50 \\
\hline MATEUS JOSÉ FERIGOLO-ME & Argila & 4 \\
\hline DESCONZI E CIA LTDA & Argila & 26,18 \\
\hline BERLEZE E CIA LTDA & Argila & 17,6 \\
\hline SOCIEDADE VICENTE PALLOTTI & Argila & 82,23 \\
\hline IRMĀOS DALLA PORTA LTDA & Argila & 8,85 \\
\hline
\end{tabular}


Tab. 2. continuação

\begin{tabular}{|c|c|c|}
\hline CERÂMICA SANTA MARIA LTDA & Argila & 14,95 \\
\hline MARIA IRENE MORGENTAL TOMAZETTI- & Argila & 4 \\
\hline KIPPER INDUSTRIAS CERÂMICAS S/A & Argila/Taguá & 71,91 \\
\hline PESSOA JURIDICA NAO CADASTRADA & Argila & 29,7 \\
\hline JOSÉ RENATO SACCOL-FI & Argila & 1,5 \\
\hline OLARIA SACCOL LTDA & Argila & 3 \\
\hline PARCIANELO DENARDI CIA LTDA & Argila & 1 \\
\hline OLARIA SARTURI LTDA & Argila & 4 \\
\hline VITELIO BEVILAQUA E CIA LTDA & Argila & 10 \\
\hline CERÂMICA TERRACOTA LTDA & Argila & 1 \\
\hline PESSOA JURIDICA NAO CADASTRADA & Argila & 1 \\
\hline ILSON HALEU DA SILVA & Basalto & 132,09 \\
\hline COPETRAN-COMÉRCIO DE PEDRAS E TR & Basalto & 9,5 \\
\hline LEMOS DANOVA ENGENHARIA E EMPREN & Basalto & 10 \\
\hline CONSTRUTORA SULTEPA SA & Basalto & 49 \\
\hline BRITA PINHAL INDUSTRIA E COMÉRCIO & Basalto & 18,16 \\
\hline IRUA RAMOS COELHO & Basalto & 20 \\
\hline COMERCIAL DE PEDRAS FOGACA LTDA & Basalto & 10 \\
\hline VALMOR DOMINGUES MARIN NIQUE & Caulim & 966,02 \\
\hline SANTAMATE IND COM IMP E EXP LTDA & Caulim & 940,45 \\
\hline EGARN KLEIN & Gema & 1000 \\
\hline LUIZ RENATO ANDRADE DE FREITAS-F & Saibro & 9,66 \\
\hline WALDEMAR DA COSTA TAVARES - ME & Saibro & 2 \\
\hline EXTRAÇÃO DE MINERAIS JOANINA LTDA & Saibro & 2 \\
\hline
\end{tabular}


Carlos Alberto da Fonseca Pires

Luis Eduardo Robaina LauRindo Bertoldo

LAGEOLAM - Lab. de Geologia Ambiental Departamento de Geociências - CCNE Universidade Federal de Santa Maria Santa Maria, RS - Brasil 